\title{
JPSE
}

(Journal of Physical Science and Engineering)

\begin{tabular}{l}
\hline Received \\
16 May 2021 \\
Revised \\
14 June 2021 \\
\\
Accepted for Publication \\
29 June 2021 \\
Published \\
04 July 2021
\end{tabular}

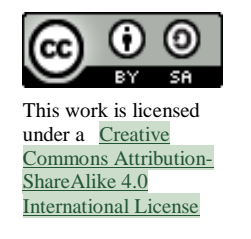

\section{The Effects of Potentiostat Scan Rate Variation on Impedance Value, Topography, and Morphology of the Polyaniline Thin Film}

\author{
I Sa'diyah and N P Putri* \\ Department of Physics, Faculty of Mathematics and Natural Sciences, Universitas Negeri Surabaya, \\ Jl. Ketintang, Surabaya, 60231, Indonesia. \\ *E-mail: nugrahaniprimary@unesa.ac.id
}

\begin{abstract}
The effects of potentiostat scan rate on the impedance, topography, and morphology of the Polyaniline (PANi) thin film has observed in this study. PANi has deposited on the Quartz Crystal Microbalance (QCM) surface with various scan rates, and changes in the impedance value have observed through an impedance analyzer test. Topography Measurement System (TMS) has observed the layer topography, while the layer morphology has observed using optical microscopy and Scanning Electron Microscope (SEM). The results have shown that the best sample has a scan rate of $10 \mathrm{mV} / \mathrm{s}$, with a low impedance value indicating the layer has rigid. The variation in scan rate can affect the impedance value, but it is not significant and does not indicate a damping effect on QCM. A homogeneous layer is deposited at a low scan rate from topography and morphological observations, while a high scan rate results in an inhomogeneous layer.

Keywords: PANi, scan rate, electropolymerization.
\end{abstract}

\section{Introduction}

Conductive polymers have high electrical conductivity values than conventional polymers, so they are widely applied in electronics [1] such as sensors, anti-corrosion coatings, batteries, capacitors, photovoltaics and other electronic fields. With this application, a deposition method that produces a thin film is needed [2]. The conductivity of the conjugated organic polymer adjusted by chemical dipping modification. The conductive polymer material that widely developed in research is Polyaniline (PANi) as an electronic device such as a sensor, one of which is that the gas sensor can detect various gases, including aroma sensors [3], free radicals [4], and alcohol [5].

PANi is a synthesis of aniline with oxidants and acid solutions as dopants. Among other conductive polymers such as Polypirol (Ppy), Polydiasethylene (Pda), Polyacetylene (PA), and Polithiophen (PT), PANi has good stability [6] and high electrical conductivity [7]. Based on the degree of oxidation, PANi divided into 3 phases, namely emeraldine base (EB), which is half-reduced with dark blue, fully reduced Leucomeraldine Base (LB) in yellow/transparent, and Pernigraniline Base (PB) is fully oxidized in purple [8]. The three PANi phases are isolative [9]. The EB phase can transform into conductive by doping a strong acid (protonic) such as $\mathrm{HCl}$ or $\mathrm{H}_{2} \mathrm{SO}_{4}$ to form Emeraldine Salt (ES), which is dark green and has a high electrical conductivity value of up to $100 \mathrm{~S} / \mathrm{cm}$ [10] depending on the level of doping. PANi in the ES phase can be returned to the EB phase by base doping (deprotonation) such as $\mathrm{NaOH}$ or $\mathrm{NH}_{4} \mathrm{OH}$.

Meanwhile, PB and LB phases can be conductive when doped with protonic acid, but the resulting electrical conductivity is low [11]. The PANi phase widely used in research is Emeraldine because PANi has stable properties and is difficult to dissolve. PANi can synthesize chemically and electrochemically. PANi, which chemically synthesize, consisting of oxidation and interfacial polymerization, will produce a powder. In contrast, the electrochemical method will produce a thin film that can make it easier to apply as an active ingredient of the Quartz Crystal Microbalance (QCM) sensor. 
The QCM is a piezoelectric sensor consisting of a thin quartz crystal and the two sides coated with silver or gold electrodes [12]. The working principle of QCM based on changes in resonant frequency due to changes in mass, according to the Saurbrey equation [13]. The shift in resonant frequency in the quartz crystal will be proportional to the increase in mass on the crystal surface [14]. This shift can observe using an impedance analyzer characterization [15]. The active ingredient layer deposited on top of the QCM must be rigid because the elastic layer can produce a viscoelastic effect (damping) on QCM [16]. Impedance measurements carried out to determine the damping effect caused by coatings on the QCM surface [15]. A considerable impedance value (> $100 \Omega$ ) indicates a significant damping effect on QCM so that the sensor cannot function properly [17].

There are several deposition methods of PANi layer which have done by many previous researchers, including that reported by Rahayu et al. [18], which used the surface polymerization method. Rahayu et al. [18] reported that the concentration and deposition time of PANi did not affect the damping of QCM despite powder agglomeration PANi which deposited above the QCM. Another study also reported by Putri et al. [17], who used the spin coating method, showing that the deposition carried out at low rotational speeds could affect the damping effect on QCM due to the PANi agglomeration. In addition, Sazou et al. [19] reported that the electro polymerization method potentiostats at scan rates of $10 \mathrm{mV} / \mathrm{s}, 20 \mathrm{mV} / \mathrm{s}$, and $50 \mathrm{mV} / \mathrm{s}$ for seven cycles affect the voltammogram and morphology. A low scan rate produces peaks voltammogram that low and homogeneous morphology. In this article, the researchers report the PANi thin layer synthesis results, which deposited on the $10 \mathrm{MHz}$ QCM sensor using the potentiostat method at scan rate variation to determine effects on impedance value, topography and morphology of the PANi thin film.

\section{Methods}

\subsection{Experimental Method}

In this study, PANi deposition on the QCM surface carried out by the potentiostat electropolymerization method using the Gamry Reference 3000 Potentiostat/Galvanostat. QCM with a silver electrode as a working electrode, platinum as a counter electrode, and $\mathrm{Ag} / \mathrm{AgCl}$ as a reference electrode. The solutions made consisted of $0.4 \mathrm{M}$ Aniline and $30 \mathrm{ml} \mathrm{HCl}$ with different concentrations $(\mathrm{HCl} 1=0.4 \mathrm{M}, \mathrm{HCl} 2=$ $0.5 \mathrm{M}$, and $\mathrm{HCl} 3=0.6 \mathrm{M}$ ). Electropolymerization was carried out with a potential range of $-1.0 \mathrm{~V}$ to $1.0 \mathrm{~V}$ for 10 seconds with a scan rate variation of $10-50 \mathrm{mV} / \mathrm{s}$. Polymerization occurs when the input voltage is connected to the three electrodes to form a thin PANi layer on the surface of the QCM electrode. After forming a layer, QCM was dried in an oven at $50^{\circ}$ for 10 minutes. Then the sample measured for the impedance value using the Omicron Bode 100 impedance analyzer (at the Department of Physics, Universitas Brawijaya) to determine the QCM impedance value. Impedance measurements carried out before and after the QCM coated with PANi. The topography of the PANi layer formed observed using TMS-TopMap 1200, while to determine the morphology, characterization carried out using an Optical Microscope (MO) and Scanning Electron Microscope (SEM).

\subsection{Theoretical Method}

The results of the QCM impedance test are analyzed theoretically to determine the magnitude of the shift in the resonant frequency so that it can affect the mass change on the QCM surface using the Saurbrey equation (Eq. 1) [20],

$$
\Delta f=\frac{2 f_{0}^{2}}{\sqrt{\rho_{q} \cdot \mu_{q}}} \frac{\Delta m}{A} .
$$

Where $\Delta f$ indicates the change in frequency $(\mathrm{Hz}), f_{0}$ indicates the quartz crystal resonance frequency $(\mathrm{Hz}), \rho_{q}$ is crystal density $\left(2.648 \mathrm{~g} / \mathrm{cm}^{3}\right), \mu_{q}$ is quartz modulus $\left(2.947 \times 10^{-11} \mathrm{~g} / \mathrm{cm} . \mathrm{s}^{2}\right), \Delta m$ is an increase in mass $(\mathrm{g})$, and $A$ is the crystal surface area $\left(\mathrm{m}^{2}\right)$. The resonant frequency $\left(f_{0}\right)$ of QCM studied was 10 $\mathrm{MHz}$ with the quartz crystal diameter $(d)$ is $4 \mathrm{~mm}$ and surface area of $12.56 \mathrm{~mm}^{2}$.

\section{Results and Discussion}

3.1. Results Cyclic Voltammetry of PANi Deposition

PANi electropolymerization to produce a voltammogram carried out with one scan/cycle according to the results, as shown in Figure 1. Previous researchers [21] reported that the ideal number of cycles is 


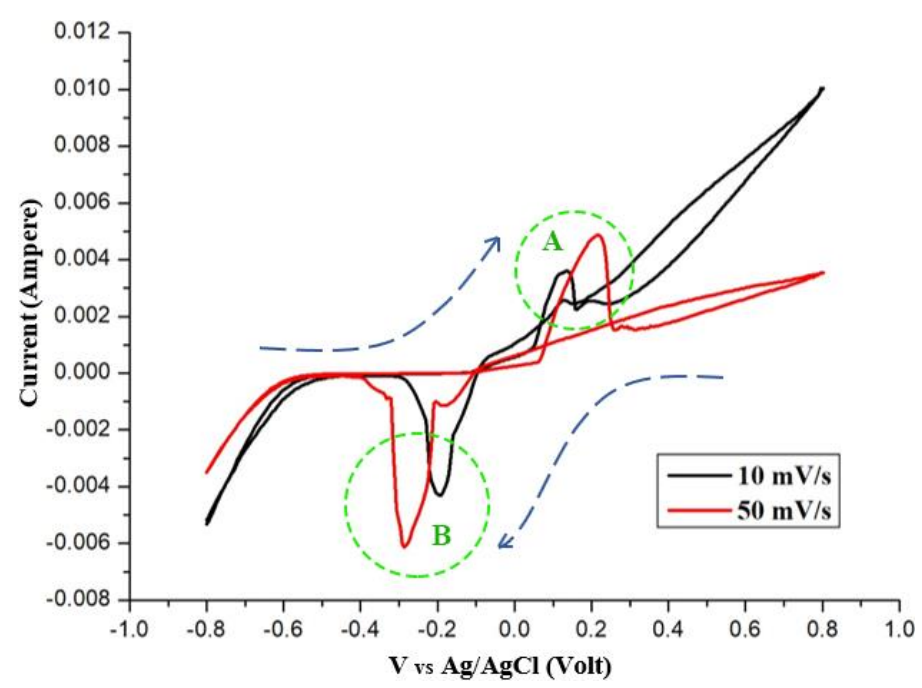

Figure 1. Cyclic voltammogram of the PANi $0.5 \mathrm{M}$ layer at a scan rate of $10 \mathrm{mV} / \mathrm{s}$ and $50 \mathrm{mV} / \mathrm{s}$.

a maximum of 10 cycles because the polymerization carried out electrochemically will make the ions bind and form a layer. If the polymerization cycle is more than ideal, it will produce a thick and easily degraded layer from the substrate surface. Scan rates carried out in the range of $10-50 \mathrm{mV} / \mathrm{s}$ have triggered the polymerization of PANi, which marked by the presence of oxidation-reduction peaks.

Based on the resulting voltammogram, a peak oxidation-reduction current indicates the stability of the PANi. In Figure 1, there is an oxidation peak (point A) and a reduction peak (point B) that occurs in the potentiostat process with a scan rate of $10 \mathrm{mV} / \mathrm{s}$ and $50 \mathrm{mV} / \mathrm{s}$. The difference in scan rate has an impact on the shift of the oxidation and reduction peaks. It is proven that at the scan rate of $10 \mathrm{mV} / \mathrm{s}$, the oxidation peak occurs in the potential range of 0.05 to $0.16 \mathrm{~V}$, while the $50 \mathrm{mV} / \mathrm{s}$ scan rate occurs in the 0.06 to $0.26 \mathrm{~V}$ potential range. At a scan rate of $10 \mathrm{mV} / \mathrm{s}$, the peak reduction occurs in the potential range of -0.08 to $-0.29 \mathrm{~V}$. In comparison, at a scan rate of $50 \mathrm{mV} / \mathrm{s}$, it appears in the potential range from -0.11 to $-0.38 \mathrm{~V}$. The oxidation peak shows a change from leucomeraldine to emeraldine phase, when approaching the potential limit of voltammograms there is a change from emeraldine to pernigraniline phase. The reduction peak indicates a shift from pernigraniline to emeraldine [22]. In the potentiostat process, the greater of scan rate, the higher the anodic current peak (oxidation peak) and the more it moves towards the positive voltage. In contrast, the reduction peak will move more towards the negative. This indicates that the electrode provides a large space when interacting with the solution [23]. This potential shift towards positive causes the intensity of the current density to increase, which indicates that more PANi deposited and the layer formed is conductive [24]. The higher peaks also indicate the faster polymerization process, but electron transfer is more negligible [25].

\subsection{Impedance Analyzer Test Results}

The QCM sensor, both before and after being coated with PANi, is conducted to an impedance test. This was done to determine the shift in the frequency-impedance curve. From the frequency-impedance curve in Figure 2, there are two types of resonant frequencies: the series resonance frequency during minimum impedance and the parallel resonance frequency during maximum impedance. QCM has a series RLC circuit so that the impedance that occurs is the minimum impedance (series resonant frequency) [26]. The resonant frequency shift occurs due to additional mass on the surface of the QCM sensor [27]. The following is the result of measuring the impedance value using an impedance analyzer.

The frequency shift is affected by the addition of dopant concentrations and differences in scan rates [18]. It appears from the impedance curve. The farthest frequency shift occurs at the scan rate of $30 \mathrm{mV} / \mathrm{s}$, showing the most significant mass increase, as shown in Table 1. The impedance value in the $\mathrm{HCl} 3$ sample deposited at the $30 \mathrm{mV} / \mathrm{s}$ scan rate also high value (Figure 3), but does not show damping effects on QCM. 


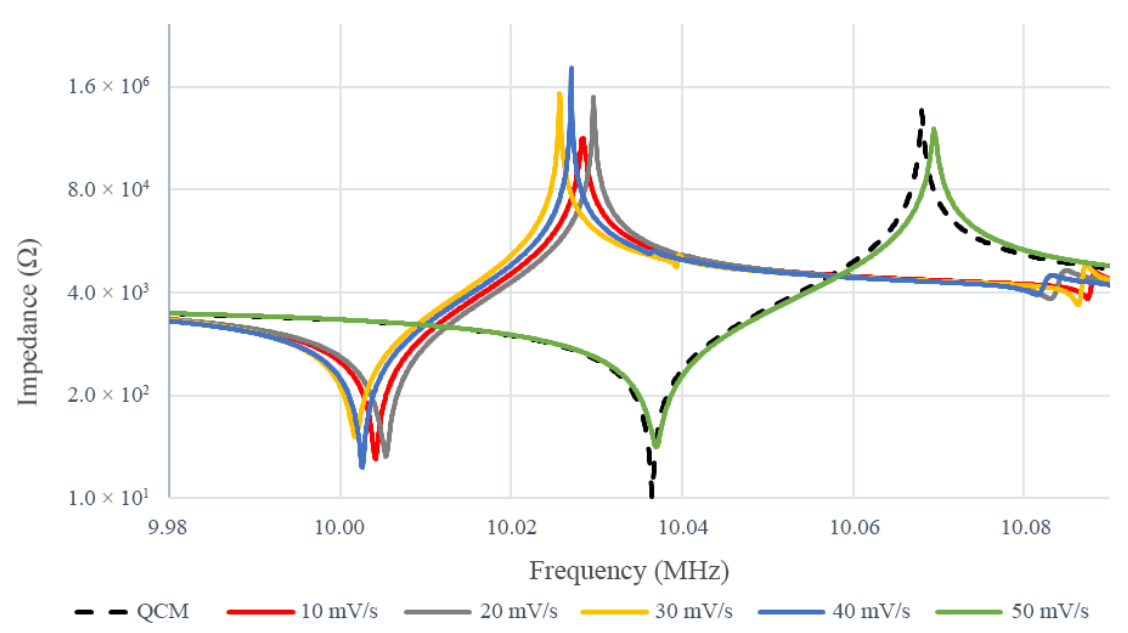

Figure 2. Changes in the frequency and impedance values of QCM on $\mathrm{HCl} 3$.

Table 1. Changes in PANi mass at the scan rate variation estimated using the Saurbrey equation.

\begin{tabular}{cccc}
\hline Scan Rate $(\mathbf{m V} / \mathbf{s})$ & HCl 1 $(\boldsymbol{\mu g})$ & HCl 2 $(\boldsymbol{\mu g})$ & HCl 3 $(\boldsymbol{\mu g})$ \\
\hline 10 & 123.11 & 122.78 & 128.55 \\
\hline 20 & 129.02 & 126.22 & 128.02 \\
\hline 30 & 123.43 & 121.79 & 130.68 \\
\hline 40 & 126.14 & 123.89 & 129.48 \\
\hline 50 & 109.57 & 129.24 & 124.30 \\
\hline
\end{tabular}

Saurbrey's equation explains that the more PANi mass deposited on the QCM surface, the more significant the frequency change of QCM [18]. Excessive frequency shifting will cause a damping effect so that the sensor cannot function properly. The peak impedance curve that looks blunt also indicates a damping effect on QCM. In Figure 2, the entire impedance curve decreases sharply, meaning that no sample has a damping effect so that QCM can function correctly.

From Figure 3, there are two types of impedance values, namely small impedance, with values ranging from 20.54 to $47.55 \Omega$, and large impedance, with values ranging from 51.01 to $58.44 \Omega$. The small impedance value implies a small damping effect on QCM, which shows that the layer is rigid. In contrast, there is a change in the layer's properties from rigid to elastic at large impedance, which indicates a more significant damping effect [26]. The highest impedance value found at the scan rate of $30 \mathrm{mV} / \mathrm{s}$ with a concentration of $0.6 \mathrm{M}$ of $\mathrm{HCl}$. In this research, variations of scan rates and $\mathrm{HCl}$ concentrations were conducted, the impedance values for all samples are still below $100 \Omega$, which does not have a damping effect on QCM. The result of PANi thin film deposition with this potentiostat method is better than that of previous researchers in the spin coating method [17] and surface polymerization [18].

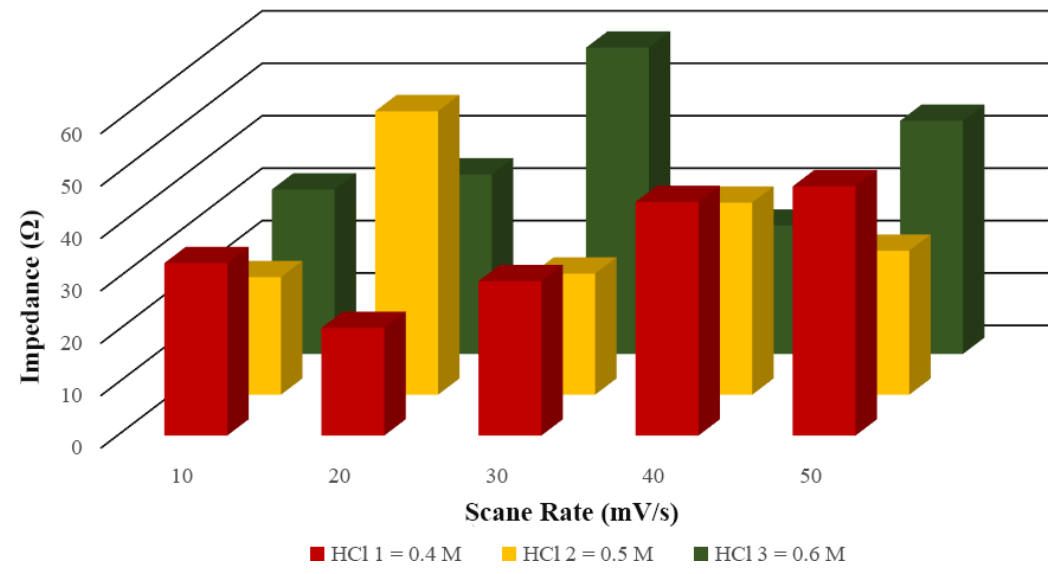

Figure 3. Graph of the impedance value at each concentration at the scan rate variation. 


\subsection{PANi Thin Film Topography Results}

The topography of the PANi layer deposited above the QCM was observed using the TMS TopMap1200 and is shown in Figures 4. Surface roughness measurements can be carried out in any target area. The level of surface height can be seen from the colour bar line located on the left [28]. It appears that the QCM surface deposited with a scan rate of $10 \mathrm{mV} / \mathrm{s}$ is covered with PANi layer well, and the layer is evenly distributed. Meanwhile, the scan rate of $50 \mathrm{mV} / \mathrm{s}$ shows an uneven surface.

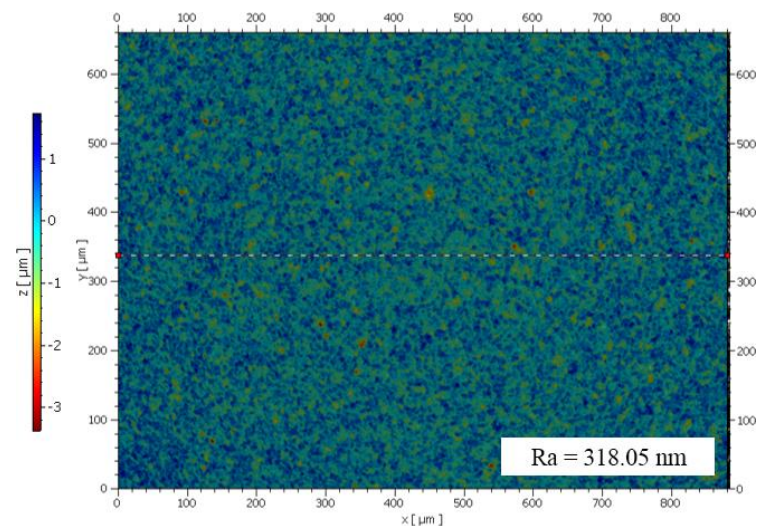

(a)

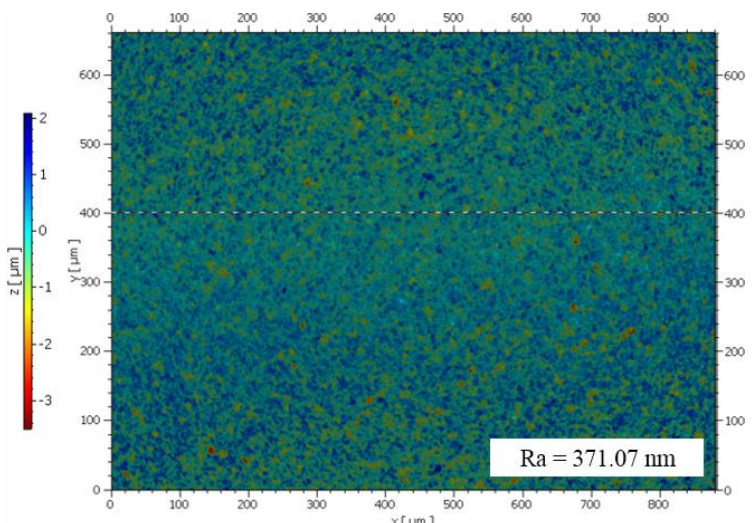

(b)

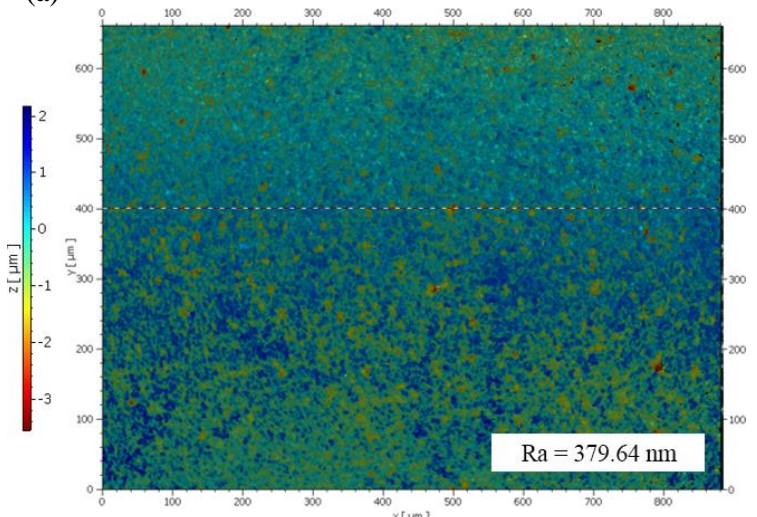

(c)

Figure 4. QCM surface topography after PANi deposition at a scan rate (a) $10 \mathrm{mV} / \mathrm{s}$, (b) $30 \mathrm{mV} / \mathrm{s}$, and (c) $50 \mathrm{mV} / \mathrm{s}$.
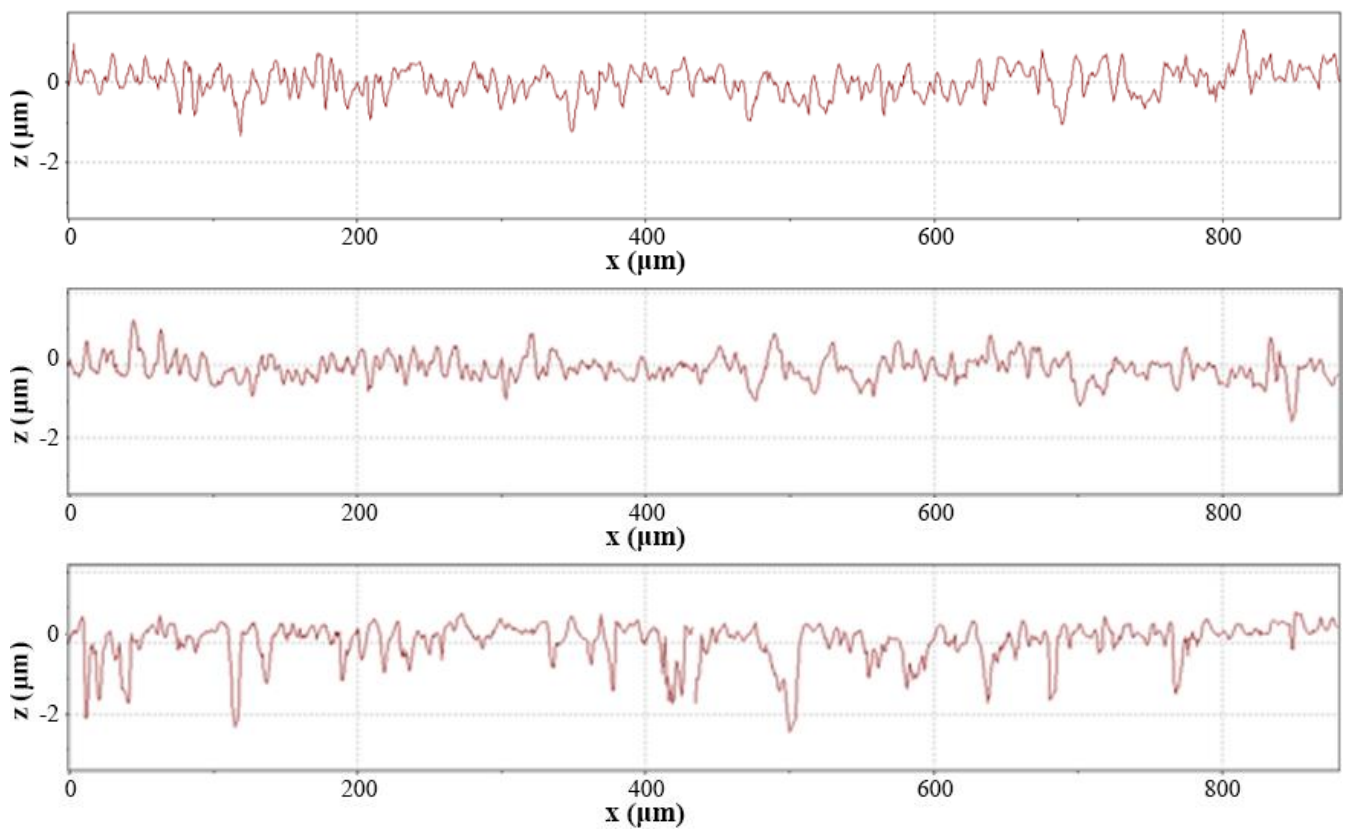

Figure 5. Graph of PANi layer roughness data on the QCM surface. 
If seen from the roughness value $(\mathrm{Ra})$ looks at the greater scan rate, then the roughness value is also greater, which indicates that the layer is getting rougher. This suggests that the PANi thin film deposition on the QCM surface potentiostat using a variation of the scan rate can affect the surface roughness properties.

The surface roughness (average roughness) of the PANi coated QCM taken on the same line in each sample presented in Figures 5. It appears that the PANi layer deposited with a scan rate of $50 \mathrm{mV} / \mathrm{s}$ has a rougher morphology than the lower scan rates $(10 \mathrm{mV} / \mathrm{s}$ and $30 \mathrm{mV} / \mathrm{s})$ because PANi deposited on the QCM surface is not evenly distributed. The level of surface roughness appears to be proportional to the morphology of the PANi layer deposited on the QCM surface.

\subsection{Results of PANi Thin Film Morphological Observations}

The morphology of PANi thin films deposited on the QCM surface is shown in Figures 6 and Figures 7 and observed using an optical microscope 200 times magnification. Figures 6 shows the difference in the dispersion of the PANi layer at different $\mathrm{HCl}$ concentrations. It appears that the PANi on $\mathrm{HCl} 1$ has a smoother layer with fewer pores which shows dispersion evenly, although there are still some parts of the QCM that have not coated (the area inside the red circle). Some black parts appear in the $\mathrm{HCl} 2$ and $\mathrm{HCl} 3$ samples, indicating an uneven deposition due to the accumulation of PANi growth on the QCM surface.

In addition to the dopant concentration, variation in scan rate can also affect the morphology of the PANi film. It is shown in Figures 7 that the lower scan rate will result in a more homogeneous layer morphology. The high scan rate makes the coating uneven and even contains pores, and this is due to the polymerization of PANi at a high scan rate that lasts a short time so that the layer deposition is uneven. Meanwhile, coating at a low scan rate will last for a longer time so that the resulting layer will deposit more evenly.

\subsection{The Results of PANi Layer Microstructure Observation}

The SEM test results in Figure 8 show the PANi $\mathrm{HCl} 3$ layer's observed morphology with a magnification of 20,000 times at a voltage of $10,000 \mathrm{kV}$. It can be seen that the QCM surface coated with PANi has a granular shape. The layer formed on the surface of QCM looks agglomeration like corals, and there is a lot of black colours that indicate the presence of pores or space. These pores are QCM surfaces which not coated with PANi. This can occur due to the short coating process at a high scan rate of $50 \mathrm{mV} / \mathrm{s}$ so that PANi is not completely evenly deposited on the QCM surface.

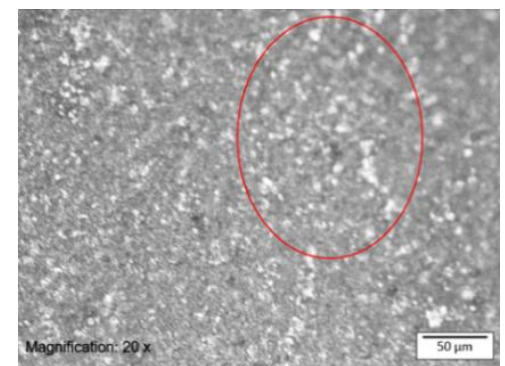

(a)

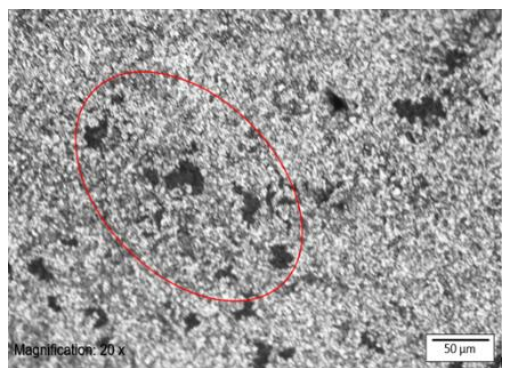

(b)

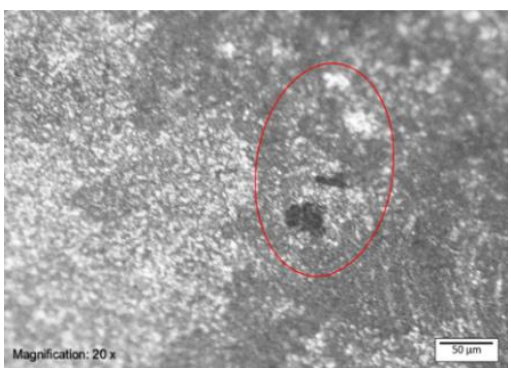

(c)

Figure 6. Morphology PANi thin film Scan rate $20 \mathrm{mV} / \mathrm{s}$ on (a) $\mathrm{HCl} 1$, (b) $\mathrm{HCl} 2$, and (c) $\mathrm{HCl} 3$.

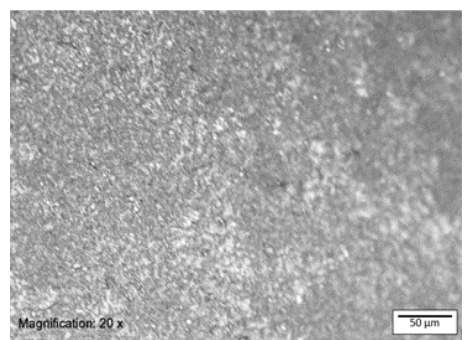

(a)

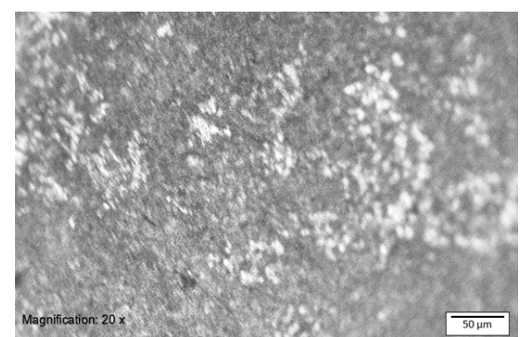

(b)

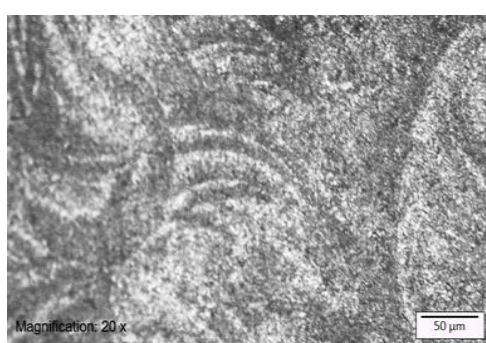

(c)

Figure 7. PANi layer morphology at variation scan rates (a) $10 \mathrm{mV} / \mathrm{s}$, (b) $30 \mathrm{mV} / \mathrm{s}$, and (c) $50 \mathrm{mV} / \mathrm{s}$. 


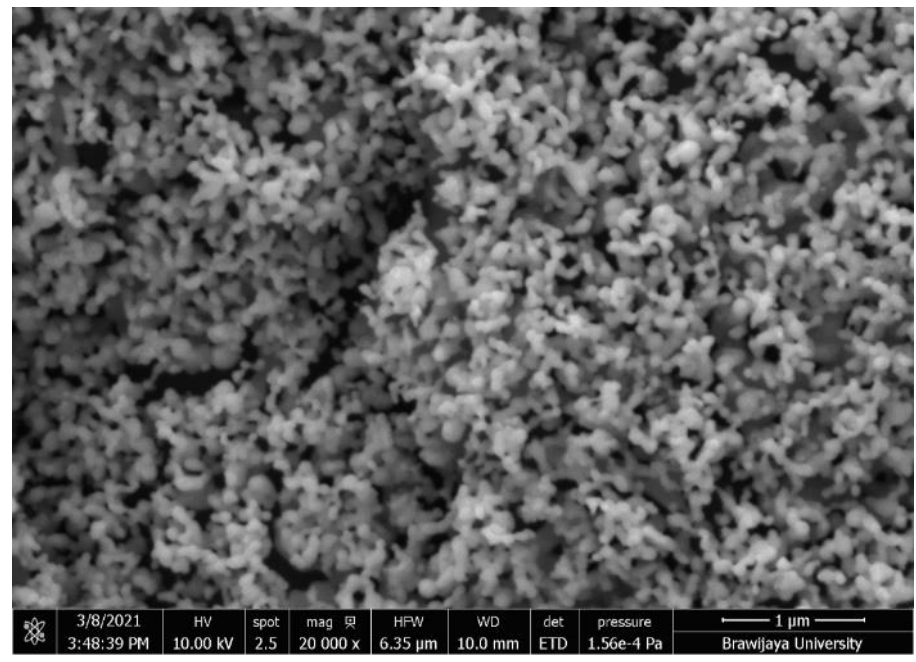

Figure 8. Morphology of PANi HCl 3 layer with a scan rate of $50 \mathrm{mV} / \mathrm{s}$.

\section{Conclusion}

The synthesis of PANi thin film deposited at QCM showed that scan rate during the deposition process could affect the impedance, topography, and morphology. A low scan rate produces low impedance and roughness values and homogeneous layer morphology. While at a significant scan rate, it produces high impedance and roughness values and not evenly dispersed layers. However, no one has a damping effect on the QCM.

\section{Acknowledgement}

Acknowledgement conveyed to the Sensor Laboratory of the Department of Physics Universitas Brawijaya, the Central Laboratory of Biological Sciences (LSIH) Universitas Brawijaya, the Materials Laboratory and the IsDB Laboratory of the Department of Physics Universitas Negeri Surabaya, and Instrumentation Laboratory of the Department of Chemistry Universitas Negeri Surabaya which provided facilities and convenience in the characterization process for this research.

\section{Reference}

[1] A. Aspi, M. B. Malino, and B. P. Lapanporo, "Analisis data spektrum spektroskopi FT-IR untuk menentukan tingkat oksidasi polianilin," Prima Fis., vol. 1, no. 2, pp. 92-96, 2013, doi: 10.26418/pf.v1i2.3066.

[2] V. Sabatini et al., "A combined XRD, solvatochromic, and cyclic voltammetric study of poly (3,4-Ethylenedioxythiophene) doped with sulfonated polyarylethersulfones: Towards new conducting polymers," Polymers (Basel)., vol. 10, no. 7, p. 770, 2018, doi: 10.3390/polym10070770.

[3] L. Tiggemann et al., "Low-cost gas sensors with polyaniline film for aroma detection," J. Food Eng., vol. 180, pp. 16-21, 2016, doi: 10.1016/j.jfoodeng.2016.02.006.

[4] S. Banerjee, D. Konwar, and A. Kumar, "Polyaniline nanofiber reinforced nanocomposite coated quartz crystal microbalance based highly sensitive free radical sensors," Sensors and Actuators B: Chem., vol. 171-172, pp. 924-931, 2012, doi: 10.1016/j.snb.2012.06.005.

[5] M. H. Shinen, F. O. Essa, and A. S. Naji, "Study the sensitivity of quartz crystal microbalance (QCM) sensor coated with different thickness of polyaniline for determination vapors of ether, chloroform, carbon tetrachloride and ethyl acetate," Chem. Mater. Res., vol. 6, no. 3, pp. 7-12, 2014.

[6] R. H. Wibawanto and D. Darminto, "Elektropolimerisasi film polianilin dengan metode galvanostatik dan pengukuran laju pertumbuhannya," JFA (J. Fis. Aplikasinya), vol. 8, no. 1, pp. 1-5, 2012, doi: 10.12962/j24604682.v8i1.859.

[7] H. Karami, M. G. Asadi, and M. Mansoori, "Pulse electropolymerization and the characterization of polyaniline nanofibers," Electrochim. Acta, vol. 61, pp. 154-164, 2012, doi: 10.1016/j.electacta.2011.11.097. 
[8] R. Bagherzadeh, M. Gorji, M. S. S. Bafgi, and N. Saveh-Shemshaki, "Electrospun conductive nanofibers for electronics," in Electrospun Nanofibers. Duxford, UK: Woodhead Publishing, 2017, ch. 18, pp. 467-519.

[9] M. N. Chomari and D. H. Kusumawati, "Variasi molaritas H2SO4 pada polianilin/H2SO4," Sains \& Matem., vol. 1, no.1, pp. 29-32, 2012.

[10] N. Savest et al., "Electrospun conductive mats from PANi-ionic liquid blends," J. Electrostat., vol. 96, pp. 40-44, 2018, doi: 10.1016/j.elstat.2018.09.007.

[11] N. K. Jangid, S. Jadoun, and N. Kaur, "A review on high-throughput synthesis, deposition of thin films and properties of polyaniline," European Polymer J., vol. 125, p. 109485, 2020, doi: 10.1016/j.eurpolymj.2020.109485.

[12] L. A. Didik, Y. Yahdi, and M. Masruroh, "Improvement QCM quality by polystyrene coating and bovine serum albumin as immobilization agent," J. Ilm. Pendidik. Fis. Al-Biruni, vol. 8, no. 1, pp. 35-41, 2019, doi: 10.24042/jipfalbiruni.v8i1.3716.

[13] Rouhillah, M. Rivai, and T. A. Sardjono, "Karakterisasi frekuensi harmonisa sensor quartz crystal microbalance sebagai identifikasi gas," in Pros. SENTIA 2015, Malang, Indonesia, vol. 7 , 2015, pp. 66-71.

[14] F. Wahyuni, S. P. Sakti, U. P. Juswono, F. Irawati, and N. Chabi, "Design of cell construction for immunosensor based quartz crystal microbalance (QCM)," Natural B: J. Health and Environt. Sci., vol. 1, no. 4, pp. 305-311, 2012, doi: 10.21776/ub.natural-b.2012.001.04.2.

[15] S. P. Sakti, E. R. N. Akbar, D. D. Kamasi, and A. Naba, "Impedance measurement of the quartz crystal microbalance using phase gain detector and digital storage oscilloscope," IOP Conf. Ser.: Mater. Sci. Eng., vol. 546, no. 4, p. 042040, 2019, doi: 10.1088/1757-899X/546/4/042040.

[16] G. C. DeNolf et al., "High frequency rheometry of viscoelastic coatings with the quartz crystal microbalance," Langmuir, vol. 27, no. 16, pp. 9873-9879, 2011, doi: 10.1021/1a200646h.

[17] N. P. Putri et al., "Solvent effect on viscoelastic behaviour and morphology of polyaniline coating at QCM sensor," in J. Phys.: Conf. Ser., vol. 1417, p. 012002, 2019, doi: 10.1088/17426596/1417/1/012002.

[18] E. I. P. Rahayu and N. P. Putri, "The effect of solution concentration and deposition time on viscoelasticity and morphology of polyaniline coating," J. Phys.: Conf. Ser., vol. 1491, p. 012050, 2020, doi: 10.1088/1742-6596/1491/1/012050.

[19] D. Sazou, M. Kourouzidou, and E. Pavlidou, "Potentiodynamic and potentiostatic deposition of polyaniline on stainless steel: Electrochemical and structural studies for a potential application to corrosion control," Electrochim. Acta, vol. 52, no. 13, pp. 4385-4397, 2007, doi: 10.1016/j.electacta.2006.12.020.

[20] L. A. Didik, E. Rahmawati, F. Robiandi, S. Rahayu, and D. J. D. H. Santjojo, "Determination of Polystyrene Layer Thickness and Zinc Phthalocyanine ( $\mathrm{ZnPc}$ ) with modified sauerbrey equations and scanning electron microscope (SEM)," Natural B: J. Health and Evinront. Sci., vol. 2, no. 4, pp. 331-335, 2014, doi: 10.21776/ub.natural-b.2014.002.04.6.

[21] J. Fernández, J. Bonastre, J. Molina, A. I. Del-Río, and F. Cases, "Study on the specific capacitance of an activated carbon cloth modified with reduced graphene oxide and polyaniline by cyclic voltammetry," Eur. Polym. J., vol. 92, pp. 194-203, 2017, doi: 10.1016/j.eurpolymj.2017.04.044.

[22] N. Carrillo et al., "Enzymatically synthesized polyaniline film deposition studied by simultaneous open circuit potential and electrochemical quartz crystal microbalance measurements," J. Colloid and Interface Sci., vol. 369, no. 1, pp. 103-110, 2012, doi: 10.1016/j.jcis.2011.12.021.

[23] S. Bilal, A. Akbar, and A. H. A. Shah, "Highly selective and reproducible electrochemical sensing of ascorbic acid through a conductive," Polym., vol. 11, no. 8, p. 1346, 2019, doi: 10.3390/polym11081346.

[24] J. Y. Lin, W. Y. Wang, and Y. T. Lin, "Characterization of polyaniline counter electrodes for dye-sensitized solar cells," Surf. Coatings Technol., vol. 231, pp. 171-175, 2013, doi: 10.1016/j.surfcoat.2012.06.039.

[25] L. E. Arisanti, N. P. Putri, and Munasir "Studi reversibilitas lapisan tipis polianilin hasil elektropolimerisasi," J. Fis., vol. 04, no. 01, pp. 10-13, 2015. 
[26] S. W. Fitriani, Masruroh, and S. P. Sakti, "Pengaruh ketebalan lapisan zinc phthalocynine (ZnPc) di atas permukaan polistiren/QCM terhadap sifat viskoelastis berdasarkan nilai impedansi," Brawijaya Phys. Student J., vol. 2, no.1, 2014.

[27] S. P. Sakti, N. F. Khusnah, D. J. D. H. Santjojo, Masruroh, and A. Sabarudin, "Surface modification of polystyrene coating on QCM sensor using ambient air plasma at low pressure," Mater. Today Proc., vol. 5, no. 7, pp. 15149-15154, 2018, doi: 10.1016/j.matpr.2018.04.073.

[28] S. P. Sakti, E. Rahmawati, and F. Robiandi, "Solvent effect on polystyrene surface roughness on top of QCM sensor," AIP Conf. Proc., vol. 1719, p. 030017, 2016, doi: 10.1063/1.4943712. 